This item was submitted to Loughborough's Research Repository by the author.

Items in Figshare are protected by copyright, with all rights reserved, unless otherwise indicated.

\title{
Utilizing a risk-based systems approach in the due diligence process for renewable energy generation
}

PLEASE CITE THE PUBLISHED VERSION

http://dx.doi.org/10.1109/JSYST.2011.2125150

PUBLISHER

(C) IEEE

VERSION

AM (Accepted Manuscript)

LICENCE

CC BY-NC-ND 4.0

\section{REPOSITORY RECORD}

Wilson, D.M., Paul Rowley, and Simon J. Watson. 2019. "Utilizing a Risk-based Systems Approach in the Due Diligence Process for Renewable Energy Generation”. figshare. https://hdl.handle.net/2134/13050. 
This item was submitted to Loughborough's Institutional Repository (https://dspace.lboro.ac.uk/) by the author and is made available under the following Creative Commons Licence conditions.

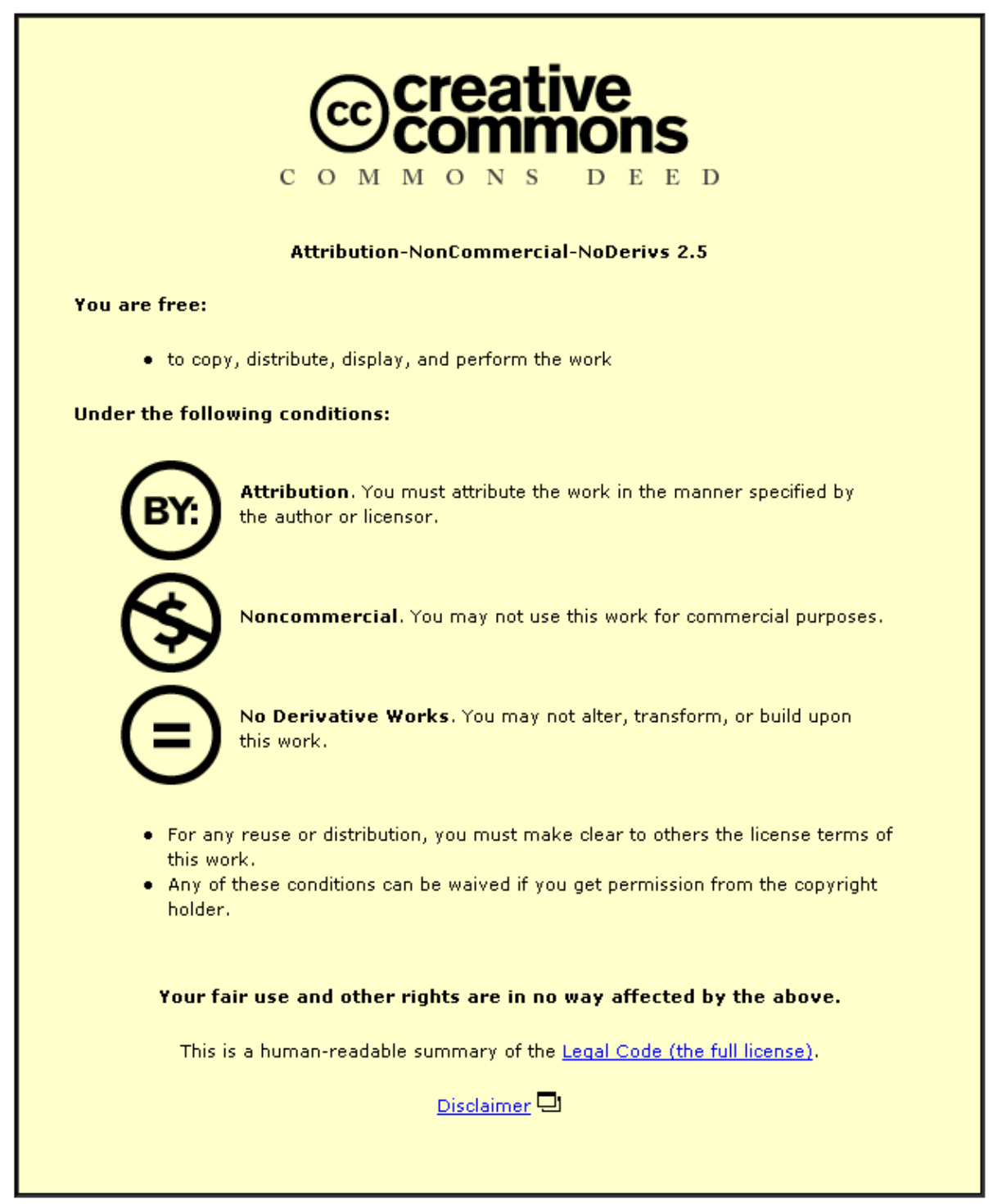

For the full text of this licence, please go to: http://creativecommons.org/licenses/by-nc-nd/2.5/ 


\title{
Utilising a Risk-Based Systems Approach in the Due Diligence Process for Renewable Energy Generation
}

\author{
Daniel M. Wilson, Paul N. Rowley, and Simon J. Watson, Member, IEEE
}

\begin{abstract}
The commercial viability of a marine renewable energy technology is impacted by a range of holistic factors related not only to the performance of the generating device, but also the characteristics of the system-of-systems within which the device operates. In this work, an investment risk assessment methodology is presented that takes account of a wide range of whole-system parameters, and provides a bridge between a device-centric evidence base and the wider systems-level data that is required in order to effectively assess the case for a specific investment. Within the paper, a system modelling framework is presented, and a case study assessment is conducted to illustrate the application of the proposed approach. The results indicate that by considering a proposed scheme in terms of both its efficacy as an operating system, along with specific lifecycle factors from concept to disposal, risks and costs can be identified in a systematic and justifiable manner. In addition, technical factors can be described in terms of their effects on the primary capability of the system, namely to produce electricity at an economically feasible cost whilst maximising return on investment.
\end{abstract}

Index Terms-marine energy, power generation economics, systems engineering, system modelling

\section{INTRODUCTION}

Due diligence can be viewed as the process by which an investor assesses the risk involved in an investment. Where this risk is related to relatively unproven technology (such as for specific renewable energy systems), engineers have an increasing role to play in informing this assessment. Within the renewable energy industry, large investors (such as utility companies or venture capitalists) are more likely to invest in a relatively unknown quantity with a limited prototype-based track record, and for which claims are made regarding the

Manuscript received November 19 2010; revised March 17, 2011

P. N. Rowley is with the Centre for Renewable Energy Systems Technology, Dept. of Electronic and Electrical Engineering, Loughborough University, Leics, LE11 3TU UK. (Corresponding author e-mail: P.N.Rowley@lboro.ac.uk; Telephone: +44 1509 635345; fax: +44 1509 635341).

D. M. Wilson was formerly with the Dept of Electronic and Electrical Engineering, Loughborough University and is now with Frazer-Nash Consultancy (Telephone: +44 11792262 42; fax: +44 117922 6524; e-mail: d.wilson@fnc.co.uk).

S.J. Watson is with the Centre for Renewable Energy Systems Technology, Dept. of Electronic and Electrical Engineering, Loughborough University. (email: S.J. Watson@lboro.ac.uk). potential of the device with further development.

A device developer's claims will often relate to technical parameters such as conversion efficiency, and survival thresholds. Based on experience within marine renewables, Watson et al [1] demonstrate that a technology can only be assessed in terms of the degree to which it contributes to a 'purposeful human activity system'. For the purposes of this study it will be assumed that the primary aim of an investment is to develop a profitable generation asset.

What value can therefore be added by introduction of systems engineering principles to this due diligence activity? An integrated temporal and technical systems approach includes both a lifecycle or through-life perspective starting at requirements or concept generation (and progressing through to disposal) along with a technical perspective of the system, consisting not purely of a device, but also of a number of other sub-system elements required to support the device in its primary purpose. Therefore, the use of a systemic approach can lend confidence to the assessment and ultimately mitigate the risk that important aspects are overlooked that later develop into project-threatening issues.

To date there has been little research published on the assessment of individual renewable energy investment opportunities, although Vallen and Bullinger [2] recognise that a multi-disciplinary approach is required to fully assess the risk inherent in specific renewable energy investment opportunities. A number of empirical studies have been conducted to formulate cost estimation models for wind energy schemes. However such empirical models are by definition retrospective, and the number of projects studied is small and often comprise prototype or demonstration projects [3], [4]. As such, the degree to which these models can be robustly applied to future projects in uncertain. The use of a systems approach has also been applied to photovoltaic (PV) research and development projects [5]. This model uses a component-based approach to conduct detailed performance analysis of PV installations, and links this to a financial model which includes manufacturing, installation, operating, and maintenance costs along with parameters for energy produced and system cost [5]. However this work does not explicitly refer to risk.

Within this paper, an integrated methodology is presented, in which a Baysian approach is utilised to conceptually assess both technical and non-technical risks through the project 
lifecycle A generating system model is then proposed, which is applied using a case study of a fictional tidal energy scheme using public domain information. Shortcomings in the approach will also be identified and critically evaluated.

\section{Methodology AND MODEL BASIS}

\section{A. Bayesian Statistics}

One factor in determining risk is the confidence with which a predicted parameter value can be stated. Bayes' Theorem is a conditional probability relationship that can be expressed using (1), and allows risk to be assessed based upon both the confidence in a prediction, and the comparison of that prediction with what may have been expected.

$P(B \mid A)=\frac{P(A \mid B) P(A)}{P(B)}$

Where:

$P(A)$ is the probability of event $\mathrm{A}$, and

$P(A \mid B)$ is the probability of event $\mathrm{A}$ given that event $\mathrm{B}$ has occurred.

Bayes' Theorem can be explained by considering a set of unobservable events; $B_{1}, \ldots, B_{n}$ which partition the universe of possible outcomes. If the observable event $A$ occurs, the probability that $A$ has occurred given that $B_{i}$ has already occurred can be found, and from this the probability that $B_{i}$ has occurred given that $A$ has occurred can be found using (1) [6]. Hence, using a prior belief about the expected distribution of $B$ and then comparing it to the evidence, or likelihood, $A$, a posterior distribution can be developed to describe $B$.

Bayes' Theorem can therefore be used to assess the plausibility of a prediction based upon existing data from similar systems. For use in this model it is useful to take a Gaussian distribution for both $A$ and $B$ and combine these to form a probability distribution of the posterior mean as explained by Bolstad [6], and summarised in (2).

$$
\begin{aligned}
& \frac{1}{\left(s^{\prime}\right)^{2}}=\frac{n_{p}}{s^{2}}+\frac{n_{l}}{\sigma^{2}} \\
& m^{\prime}=m\left(\frac{n_{p} / s^{2}}{n_{l} / \sigma^{2}+n_{p} / s^{2}}\right)+\bar{y}\left(\frac{n_{l} / \sigma^{2}}{n_{l} / \sigma^{2}+n_{p} / s^{2}}\right)
\end{aligned}
$$

Where

$\Phi\left(m, s^{2}\right)$ is the prior distribution.

$\Phi\left(\bar{y}, \sigma^{2}\right)$ is the likelihood distribution.

$\Phi\left(m^{\prime},\left(s^{\prime}\right)^{2}\right)$ is the posterior distribution.

$n_{p}$ is the weight to be given to the prior distribution

$n_{l}$ is the weight to be given to the likelihood distribution

The probability that a parameter is a given value (or more correctly is in a given range) is therefore the sum of all possible distributions in that range, weighted by the probability that the distribution exists. These distributions are defined by moving the mean according to the posterior distribution, and assuming a variance such as that of the prior distribution. This distribution construction is shown in Fig 1.
Alternatively, a frequentist approach could be employed utilising experimental trial data to determine the confidence interval within which a claimed value lies, based on the distribution of trial results. However, use of a Bayesian approach also considers the plausibility of the predicted value, and allows an assessment to be made in the early stages of development when experimental data is scarce [7].

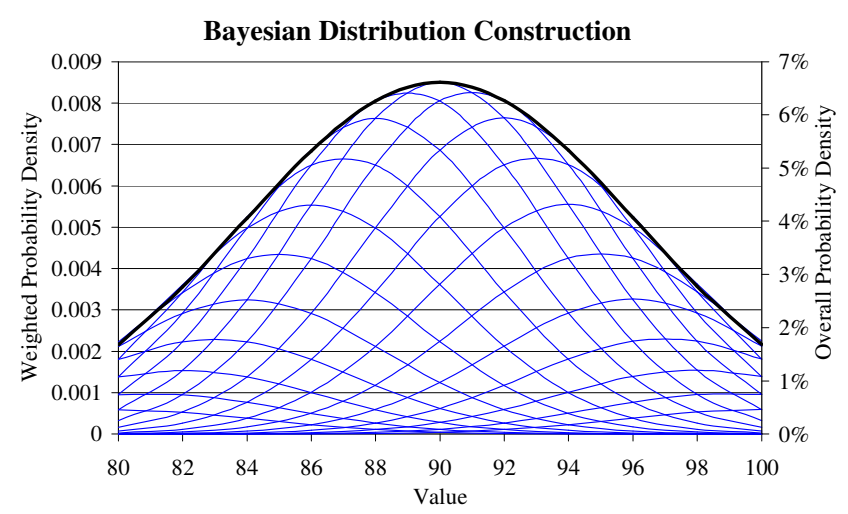

Fig 1. Bayesian Distribution Construction

\section{B. Technology Readiness Levels}

Technology Readiness Levels (TRLs) are a graduated scale developed by NASA that uses specific criteria to define the maturity of technology [8].The TRL construct uses a number of defined levels (generally 1 to 9) ranging from 'Basic principles observed and reported' at TRL 1 through to 'Actual Technology system qualified through successful mission operations' at TRL 9 [8], and focuses on the maturity of a technology in the target context. For example, whilst a marine energy converter may use commercial components, these may have a lower maturity level if they have not been used in the marine environment before. Although by their nature TRLs are subjective to some degree, the declaration of a level should be supported by sufficient evidence, particularly in the sphere of due diligence where any claims made must be fully justified. This could be achieved through a Claims-Arguments-Evidence methodology as described by Watson et al [1].

At TRL 9, there is assumed to be very little apparent technical risk in the project as the technology has been assumed to be 'mission proven'. Conversely, at TRL 1 the technology is considered to be still in the realm of scientific investigation, and there is no guarantee that the principles observed can be developed into a feasible system. TRLs can therefore be used to imply a risk distribution around the predicted cost of a scheme as discussed by Moorhouse [9].

\section{Decommissioning}

In many cases, a condition of development permission is that any proposal must be accompanied by a decommissioning plan, supported by some security to ensure that it will be carried through [10]. Decommissioning, and the risk involved, is therefore a factor that must be considered when assessing a proposed generation scheme. In the context of marine energy developments, decommissioning is assumed to include the 
removal of all elements above the sea-bed, or those which are likely to become uncovered, with foundations and deep buried cables left in situ [11], [12]. Based upon these assumptions, the cost of decommissioning an offshore wind turbine is estimated at around $£ 118,000$ per turbine ( $£ 194,000$ nominal $\left.^{1}\right)$ [12].

\section{MARINE RENEWABLE ENERGY GENERATING SySTEM MODEL}

The aim of the proposed approach is to quantify both the projected cost of energy generation for a system and the risk involved. Subsequently, various financial measures for use in investment appraisal can be derived, such as the Internal Rate of Return (IRR) or Net Present Value (NPV), and the required breakeven market price of electricity sold expressed in terms of the Levelised Energy Cost (LEC) [13].

Consistent with the Central Limit Theorem [14], it is assumed that all parameters within the model (and hence the results) can be represented using a Gaussian probability distribution, where the expected value is the mean, and the variance is a measure of uncertainty. Hence, a shift in the mean represents a change in expected cost, whereas a change in shape represents a change in the uncertainty. This approach facilitates the propagation of Gaussian errors through standard mathematical operators and ultimately gives the probability that a scheme will be profitable, given a set of economic conditions.

\section{A. System Lifecycle}

As recognised in ISO/IEC BS15288 [15] any system progresses through a lifecycle starting with a concept, and progresses through a service life to eventual disposal. Whilst the revenue from a generation system appears during the service life, costs are incurred from inception to the completion of the disposal process, or further if a continuing liability exists. To use a simplified model, the system can be considered to proceed through four stages as shown in Fig 2 . To move between these stages, a number of supporting systems are required to conduct the transformation processes).

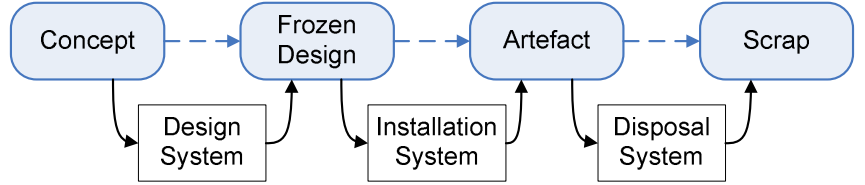

Fig 2. System Lifecycle

In the artefact (or operational) state, the system can be assessed objectively in terms of its capital expenditure (CAPEX), its Operation and Maintenance (O\&M) costs, and its performance or yield, each of which may have associated uncertainties. Each of the transformation processes also possesses associated costs and risks. Costs are related to executing the process, and risks are related to the probability that the process (or its results) does not proceed as expected. The predicted CAPEX and process costs can be adjusted to take account of this risk and allow for contingency as described later within this section.

\section{B. System Model}

In order to assess the system in its artefact state, it is necessary to define the boundaries of the system. The generation system is part of a larger Energy Supply Industry (ESI), and in the UK this operates according to the requirements of the British Electricity Transmission and Trading Arrangements (BETTA) [16].

BETTA can be considered using a scenario, as represented by the activity diagram in Fig 3, which shows the activities necessary to facilitate an increase in electricity demand from a user. The user must, ahead of time, have bought a quantity of electricity from a supplier, who in turn procures this from a generator, either directly or via an energy market. When the electricity is demanded (message 6.1), this is despatched by the generator via the transmission/distribution network. The role of the balancing sub-system is to ensure that the electricity supplied to the network matches demand, and to request balancing alterations as required.

It can be seen that the generating sub-system must deliver electrical power to the grid, sell electricity, and co-ordinate output with the balancing authority. Using a Data Flow

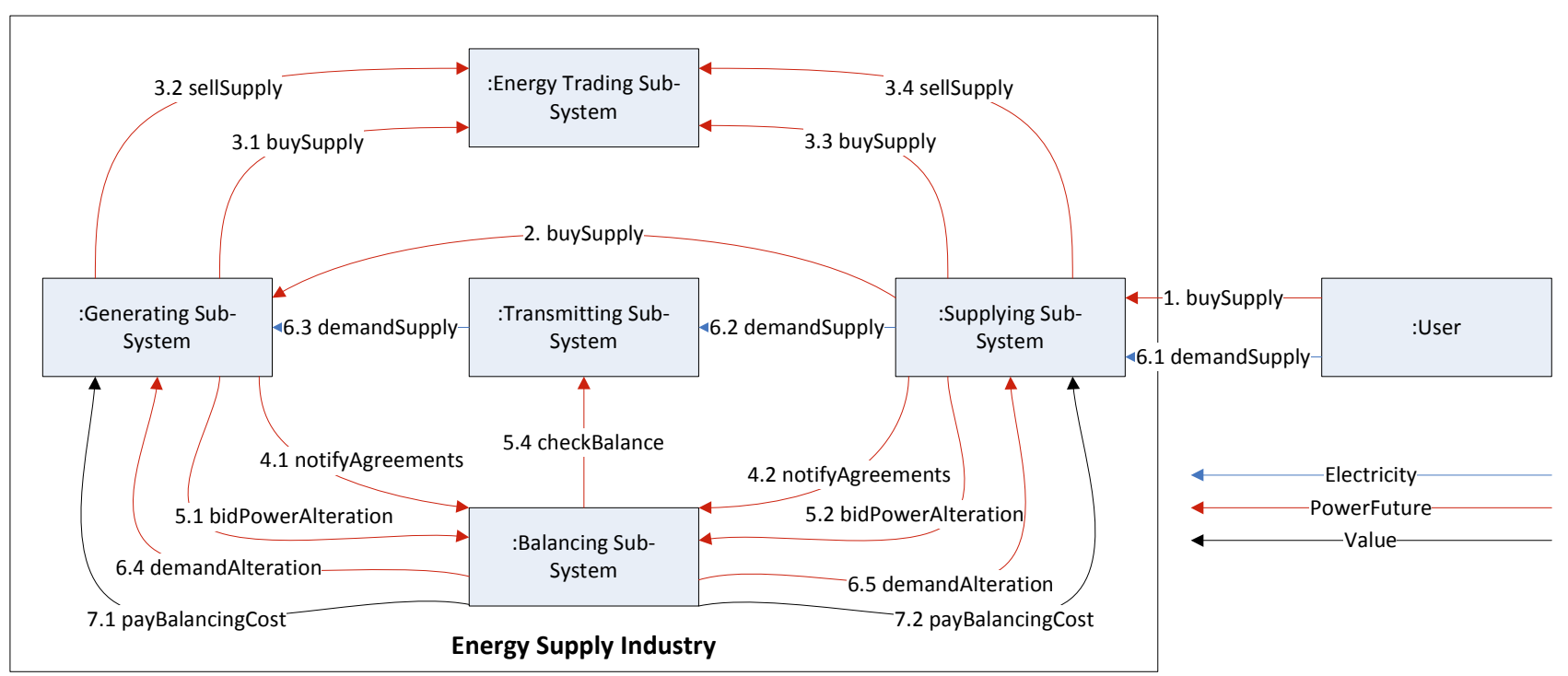

Fig 3. Energy Supply Industry Activity Diagram 
Diagram, shown in Fig 4, this functionality can be decomposed into both transformation processes and system elements. electrical energy. This energy is then conditioned to grid standard and delivered to the transmission network input point

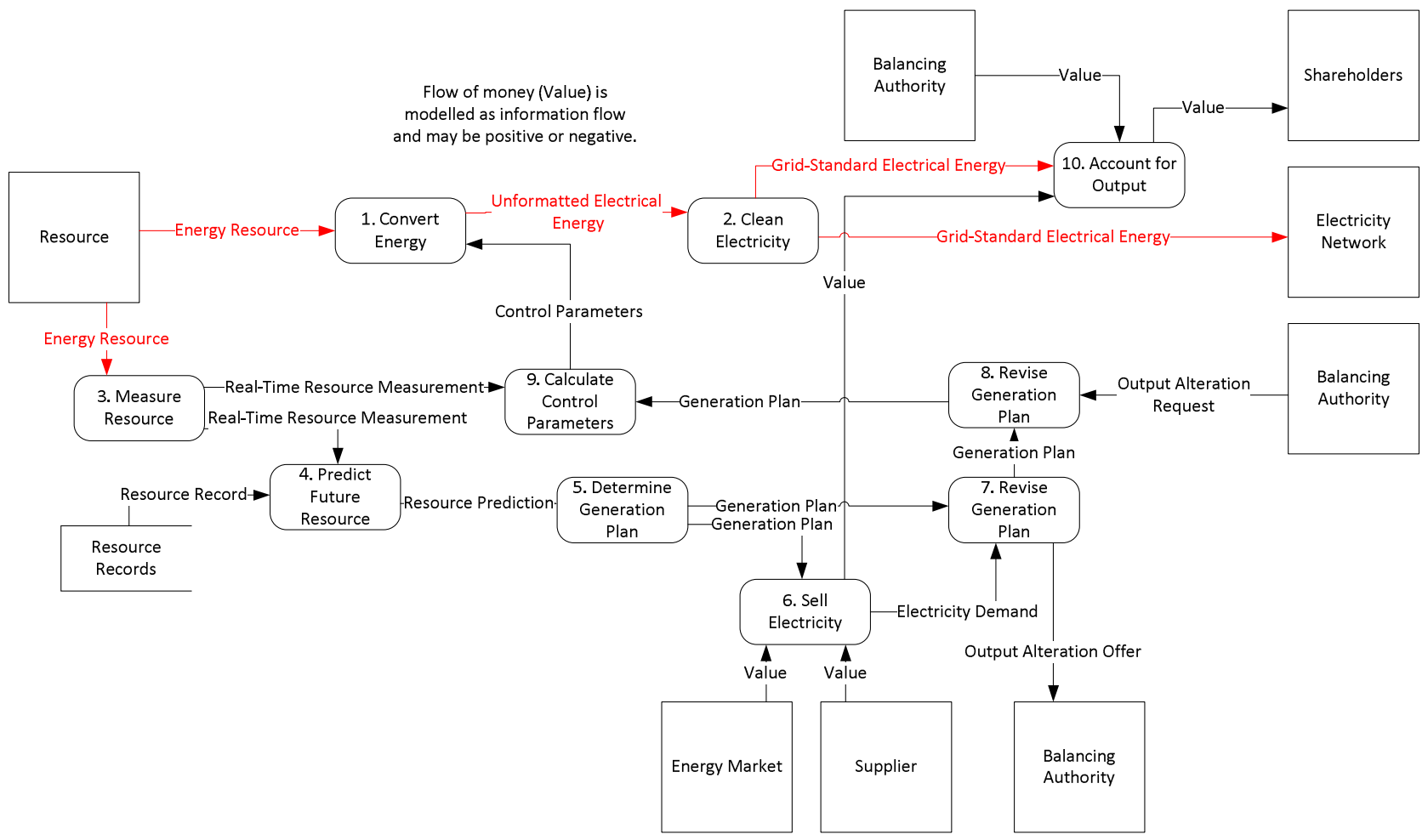

Fig 4. Generating Sub-System Data Flow Diagram

Fig 4 also illustrates the need for energy conversion and power conditioning sub-systems to convert the generated power to the required grid standard. Furthermore, a control system is required (potentially including both control equipment and human operators to make commercial decisions), along with a means by which the present and future resources are measured. Sub-systems by which communication with other ESI entities is facilitated and financial value is the transferred are also needed.

The allocation of these functions is defined in Table 1.

\begin{tabular}{ll}
\hline Element & Functions \\
\hline Device & Convert Energy \\
Grid Connection & Clean Electricity \\
Control Equipment & Determine Generation Plan \\
& Sell Electricity \\
& Calculate Control Parameters \\
& Revise Generation Plan, \\
& Account for Output \\
Resource Prediction & Predict Future Resource \\
Resource Monitoring & Measure Resource \\
Device Site & Resource (External Entity) \\
\hline
\end{tabular}
TABLE 1 FUNCTION ALLOCATION

If a requirement exists to perform these functions over a given service life, then a maintenance provision is required and thus the system model shown in Fig 5 can be derived. This shows that the generation device extracts energy from its immediate external environment which it converts into via the grid connection. The control system supports this primary activity by ensuring that the generation device is suitably configured to use the resource effectively and coordinates generation with the rest of the ESI, whilst the maintenance system ensures that the system continues to operate effectively throughout its operational life.

This model specifies a number of functions that must be fulfilled, and hence provokes consideration of how each will be met. In addition, the interrelations between elements allow the coupling between components to be assessed. A decision to deploy a particular generating device may mandate the control and support elements required, which in turn places constraints on the offshore estate that can be used. Defining the solution to these requirements allows further requirements to be propagated outwards through the system to ensure coherency. In addition, this propagation allows for options appraisal at each stage, and thus the consequence of each issue to be assessed. For example, if a device could be economically installed at a number of different sites, then the consequence for a scheme of the proposed site becoming unavailable would be reduced. 


\section{E. Design Transitional Process}

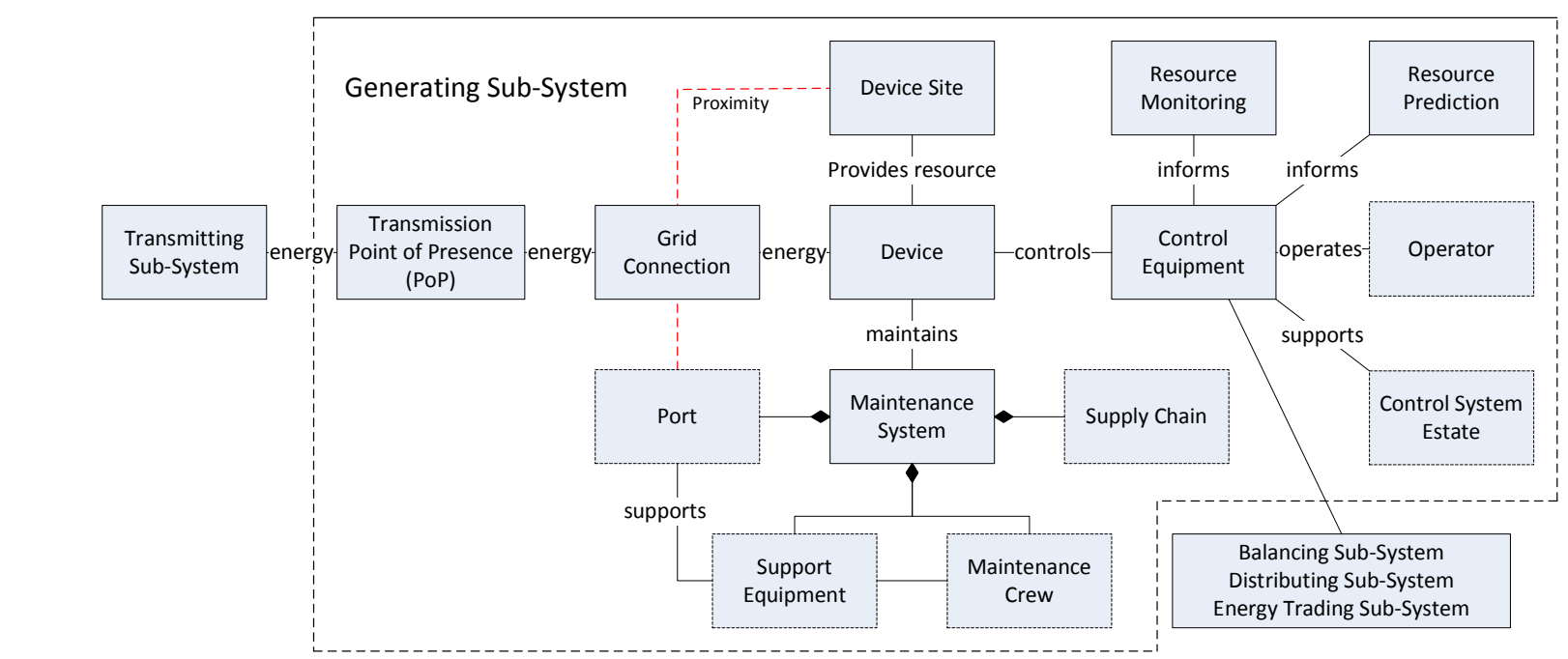

Fig 5 Generating Sub-System Model

\section{System Parameters}

A number of system level parameters can be defined for the generating system, and calculated from system element attributes as described in Table 2. These parameters can then be used to evaluate the cost of energy generated by the system.

\begin{tabular}{ll}
\hline Parameter & Description and Derivation \\
\hline Yield & $\begin{array}{l}\text { This is largely a function of the device, and } \\
\text { can be quantified in terms of the capacity and } \\
\text { capacity factor. This allows useful } \\
\text { comparisons to be made between devices of } \\
\text { different scales. Yield would be stated as the } \\
\text { energy exported to the grid over the } \\
\text { operational life of the system. }\end{array}$ \\
Capital Cost & $\begin{array}{l}\text { This is a simple sum of the capital costs of } \\
\text { O\&M Cost }\end{array}$ \\
& $\begin{array}{l}\text { This is taken as a proportion of the system } \\
\text { capital cost to allow comparison between } \\
\text { different systems. O\&M costs would largely } \\
\text { come from human resource costs and repair } \\
\text { costs based on reliability. }\end{array}$ \\
\hline TABLE 2 GENERATING SYSTEM PARAMETERS
\end{tabular}

\section{Parameter Probability Distributions}

The confidence in each of the parameters described in Table 2 can be expressed by representing its value as a probability distribution. This can be derived from declared parameters via the use of a normal distribution constructed from the mean and variance from a known data set, or from an estimate with a confidence level and error bound. A confidence distribution can also be calculated by comparing the parameter to those of similar established systems using Bayes Theorem as described in §II.A. Hence, when these factors are combined to produce a LEC (as described in later in this section) the factors can be combined as Gaussian distributions, and the uncertainty in the inputs reflected in the final results.
Using the system model defined in this paper, it can be seen that not all elements will be defined using data provided by the system developer. For example, the offshore estate existed before the system, and will continue to exist after the system has been dismantled, and so can be defined as an enduring element. Conversely, the device must be provided for the sole use of the system, and will be disposed of at the end of the service life, so is a non-enduring element. Risk exists in the design transition for both enduring and non-enduring elements, but must be assessed differently.

1) Enduring Design Risk

A key risk associated with enduring elements is that an assumption that a resource will be available is later proved to be untrue. For example, this could relate to uncertainty in obtaining development consent for a particular offshore site. As discussed earlier in this section, this risk can be expressed in terms of a contingency on the capital cost, given by the product of probability that the resource will not be available, and the consequential cost if this is the case. This product gives an overall design risk escalator with which to re-evaluate the system capital cost.

Ideally, these assessments would be made based on engineering judgement, but in the early stages of a project, accurate estimate may not be possible. A two-axis subjective scale is therefore proposed, as shown in Table 3 and Table 4, to enable an initial assessment to be made, and risks to be classified in terms of their severity.

\begin{tabular}{|c|c|c|}
\hline \multicolumn{3}{|c|}{ Consequence } \\
\hline Level & $\begin{array}{l}\text { Cost } \\
\text { Escalator }\end{array}$ & Description \\
\hline 0 & $0 \%$ & No performance degradation. \\
\hline 1 & $10 \%$ & Minor performance degradation. \\
\hline 2 & $50 \%$ & Major performance degradation \\
\hline 3 & $100 \%$ & Project critical failure. \\
\hline
\end{tabular}




\begin{tabular}{|c|c|c|}
\hline \multicolumn{3}{|c|}{ Confidence } \\
\hline Level & Confidence & Description \\
\hline 0 & $50 \%$ & $\begin{array}{l}\text { There is no evidence to support the } \\
\text { proposition that the element can be } \\
\text { used. }\end{array}$ \\
\hline 1 & $60 \%$ & $\begin{array}{l}\text { The available evidence suggests } \\
\text { that the element will be available } \\
\text { for the life of the system, but no } \\
\text { official permission exists. }\end{array}$ \\
\hline 2 & $70 \%$ & $\begin{array}{l}\text { The available evidence suggests } \\
\text { that the element will be available } \\
\text { for the life of the system, and } \\
\text { official permission and land-owners } \\
\text { consent exists. }\end{array}$ \\
\hline 3 & $80 \%$ & $\begin{array}{l}\text { The element has been used before } \\
\text { in a similar manner such as a } \\
\text { prototype or other similar device. }\end{array}$ \\
\hline 4 & $100 \%$ & $\begin{array}{l}\text { Legally binding permission has } \\
\text { been granted. }\end{array}$ \\
\hline
\end{tabular}

2) Non-Enduring Design Risk

Non-enduring design risks include uncertainties relating to both technical and organisational aspects that could lead to cost and time overruns for specific elements.

\section{a) Technical Risk}

The use of a system model encourages the identification of technical risk in the system by identifying the solution to each element. Each element solution can then be assessed in terms of its technology maturity (using TRLs), and the capital cost escalated accordingly.

\section{b) Provider Risk}

Each non-enduring element must be designed and delivered by given provider(s), whose ability to deliver will depend on both specific organisational processes in place and the skill sets present within the company. Organisational processes can be assessed using methodologies such as the Software Process Improvement and Capability dEtermination (SPICE) defined in BS ISO/IEC 15504 [17]. SPICE defines a process assessment framework for comparison with a standard (such as BS ISO/IEC 15288 [15]) and specifies required target capabilities. A risk profile is then deduced based on both the size and nature of any shortfall. This risk profile ultimately reduces to an assessment of process risk for a given organisation on a comparative None, Low, Medium or High scale, which can then be mapped to an escalation factor on the capital cost of the element in question.

For novel renewable energy schemes, intrinsic investment risk related to the ability of the developer to carry the project through to a commercial conclusion can be significant. This is partly a result of the nature of the industry whereby research and development is often conducted by small companies or academic spin-offs, potentially lacking the expertise and experience to deploy systems in an operational environment. The risk due to sub-optimal skill set availability is widely recognised [15], and whilst skills required for renewable energy projects have been categorised by project stage [18] it is problematic to empirically assess the cost implications of these risks. Thus, for the purposes of this work, these risks are identified but excluded from cost calculations until such time as justifiable cost escalation factors can be determined.

\section{3) Cost Escalation}

The identification of specific risk within the design transition may result in an increase in the overall expected cost, but should not necessarily increase the uncertainty as a proportion of the expected value. The expected cost of a risk is given by the product of the probability of occurrence and the consequential cost. Hence, by using the expected cost of a risk, the contingency added should equal the costs incurred, providing this is applied across enough risks. This means that the cost escalations applied should increase the expected value of a parameter, but not the uncertainty in it which is represented as the variance.

\section{F. Installation Transitional Process}

The installation process (in which a frozen design is transformed to an operational system), includes both construction and on-site installation of system elements. In terms of the Technical Processes defined in BS ISO/IEC 15288[15], this covers implementation through to, and including, transition. Whilst risks due to element design and the capability of providers may be realised during this stage, these risks may originate during the design phase so have been captured in the previous section. The focus of the installation analysis is therefore upon the technical process of build, installation and commissioning.

Marine energy systems experience particular technical challenges in installation due to the harsh operating environment [22]. The risks associated with these technical challenges can by assessed in terms of the technical maturity of the methods used. In a similar way to the use of TRLs to quantify design risk and escalate capital cost, the TRL of the installation method used for each non-enduring element can be assessed, and the installation cost escalated accordingly to account for this technical risk.

\section{G. Disposal Transitional Process}

In the disposal process, the sites occupied by the installed systems are returned to their original state (or as close as reasonably practicable). This process and its risk profile is similar in many ways to that of the installation process, and could be analysed in a similar manner. In reality, however, assessing the disposal process technical maturity is not possible up to 25 years hence, so disposal costs can only be included as fixed-point estimates. Furthermore, where some elements are left in situ, decisions made at the start of the project may also result in a residual ongoing liability after the 
disposal process is complete. This would constitute an additional cost, or contingency, that must be included in the overall disposal cost estimate.

\section{H. Calculation of Output Parameters}

The overall cost of the energy produced can be expressed in terms of the Levelised Energy Cost (LEC). LEC is the ratio of the sum of all through life costs to the total expected energy generated with the costs incurred and energy generated expressed in terms of their Net Present Value (NPV) [13]. LEC therefore represents the break-even price of energy for given scheme, assuming a particular discount rate to recognise the time preference in return on investment [23]. By representing both the through-life costs and energy generated in terms of probabilistic distributions, and escalating the costs to take account of the design, technical and organisational risks associated with the suppliers and resources used, the LEC calculated will also be a probabilistic distribution. The LEC distribution therefore represents the expected cost of energy, given the risk involved, and the uncertainty in the prediction

\section{Risk Identification and Ranking}

The generating system model can be seen to identify three types of risk:

- The risk that a system element (and as such the system) does not perform as expected;

- The risk that a system element provider does not deliver as expected; and

- The risk that the system is not installed or disposed of as expected.

As such, the effect of the risk intrinsic in each element and provider can be assessed in terms of the effect it has on the overall cost of energy. Using a method similar to Birnbaum's Criticality measure used in Reliability Engineering [24], the criticality of particular risk factors can be determined by partially differentiating the overall energy cost. These criticality measures can then be used to rank risks in terms of effect they have on the overall cost, and thus help target efforts to improve the risk profile.

\section{EXEMPLAR ASSESSMENT}

\section{A. Introduction}

To illustrate the model and methodology developed in this work, analysis of a fictional pre-commercial array of ten 500MW tidal stream devices in Shetland's Yell Sound has been carried out. Although fictional, the analysis is based upon the actual proposed development of a subsequently cancelled tidal stream project, and uses public-domain information published by the UK's Department for Business Innovation and Skills (BIS) $)^{2}$ [20], [25].

\section{B. Mapping to the Generating System Model}

To gain an understanding of the generation system, its

\footnotetext{
${ }^{2}$ Previously known as the Department for Trade and Industry (DTI) and The Department for Business, Enterprise and Regulatory Reform (BERR)
}

parameters must first be mapped onto the generating system model described previously and shown in Table 5. This enables a number of key risks that impact upon capital and operational costs to be identified, and technology readiness levels (TRLs) to be assessed. It is evident that most elements of the generic model can be included. However, a notable exception is that of the impact of personnel issues; in particular, the O\&M expertise is in this novel technology is held solely by the developer, and during operation, there may be lack of local expertise on which to draw. Furthermore, the bespoke nature of the device and uncertainties relating to its extended supply chain mean that component lead times may be extensive, increasing Logistic Delay Time and reducing operational availability.

The TRL for each system element can be determined through comparison of the element with a set of standard definitions such as those used by the Ministry of Defence (MOD) [8]. Due to the level of information in the public domain, each non-enduring element has been assessed as an integrated unit, although ideally the more significant system elements (such as the generating device itself) would be further decomposed into sub-systems. Using this methodology, the overall TRL for the tidal stream system has been assessed as TRL6. This assessment is based upon the nature of the generating device, which is the least mature element due to both its state of development, and the scale of the proposed changes between the tested prototype (150MW) and the proposed device for deployment (500MW).

Whole system parameters used to determine the overall costs have been extracted from published reports [20], and are shown in Table 6. Declared capital, installation and disposal cost parameters [20] are expressed with a confidence on a Low-Medium-High scale. This has been interpreted as a $10 \%$, $50 \%$ or $90 \%$ confidence of the true value falling within $\pm 10 \%$ of that declared. Using Bayes' Theorem (1), the O\&M costs have been determined by comparing predicted figures for the tidal stream device [20] with data from the UK Round 1 offshore wind farm development programme [26-30]. The generating system capacity factor has been determined by comparing mathematical modelling results obtained by the device developer with prototype test results, whilst allowing for an expected improvement factor [20].

\section{Design Process}

\section{1) Enduring Elements}

The data available to assess risks associated with enduring elements in limited, however an initial assessment can be made using the consequence levels described in Table 3 and the probability levels given in Table 4. It is judged that the offshore estate has a confidence of Level $3(80 \%)$ as planning permission was granted for the prototype, but the proposed scheme is much larger and more permanent. The consequence is assessed as Level 2 (50\% cost increase) as the device has been designed with Yell Sound as the target environment. The other enduring elements can be assessed in a similar way, and the overall system enduring risk can be calculated as the 
product of the cost escalators, which is then used to escalate the system capital cost.

\begin{tabular}{ll}
\hline Element & Solution \\
\hline Device & Tidal stream device. \\
& \\
Grid Connection & $\begin{array}{l}\text { Array sub-sea cabling running to } \\
\text { an onshore sub-station. }\end{array}$
\end{tabular}

Transmission Point of Connection to the Shetland grid at Presence the onshore sub-station.

Resource Monitoring

Estate

Maintenance

Port

Support Vessel

Maintenance Crew

Supply Chain

Control

Onshore Infrastructure A shore station will be installed on site.

Resource Prediction $\quad$ No formal provision is in place.

Control Equipment

Operator
Acoustic Doppler Current Profiler (ADCP) sensors mounted on the Tidal stream device to measure stream velocity as a primary control input.

Yell-Bigga stream to the South of the Yell Sound at around $60.5 \mathrm{~N}$, $1.18 \mathrm{~W}$.

Sullom Voe oil terminal.

A barge mounted handling system positioned by tug.

No strategy appears to be in place on how the maintenance function will be manned.

The majority of the components are currently bespoke and manufactured by the developer, and marine contractors in Tyneside and Fife, and assembled in Shetland. No long-term strategy appears to be in place.

Control equipment has been developed alongside the Tidal stream device.

No strategy appears to be in place on how the operation function will be manned.
2) Non-Enduring Elements

Non-Enduring elements are assessed in conjunction with an

Comment
The first generation device has been tested in the
operational environment. The second generation
device proposes an overhaul of the device design,
but utilising the same concept, control strategy
and power take-off method.

The grid connection does not differ markedly from that currently operational for offshore wind turbines.

Shetland is not currently connected to the UK Enduring grid [19], and grid connection is more expensive in Shetland than elsewhere, but this has not been costed [20].[25]

The ADCP is as used in all testing so is tested in Nonthe prototype operational environment.

Enduring

All testing has taken place on the same site.

Enduring

Sullom Voe is a large oil terminal port around $12 \mathrm{~km}$ shipping distance from the proposed site.

The handling system has been used in testing at a Nongreater regularity than would be expected Enduring operationally.

Currently all maintenance has been conducted by Nonthe developer's engineers. In operation, local Enduring staff would be required, and would need training to complete these tasks.

Engineering (with exception of the oil terminal) does not form an appreciable proportion of the Shetlands economy [21] so it is assumed that the first tier supply chain would need to extend from the mainland. The device concept is largely bespoke so is likely to be dependent on a small supplier base.

Planning permission has been previously granted for test activity and a shore station.

Tidal streams are relatively predictable, so a formal prediction function is probably not required.

Control development has taken place through Non-

testing, and whilst not fully optimised, this Enduring appears to be in hand.

See Maintenance Crew.

Non-

Enduring
Enduring

Non-

Enduring 
analysis of the organisations responsible for providing them. In this case it is not possible to make a justified assessment of the organisations involved based on public domain data, but if this was available, a risk level could be obtained for each supplier, which can then be mapped to a cost escalator as described in §III.E.2). A weighted average of the cost escalators can then be derived based on the relative capital costs of the elements provided by each supplier. This escalator is then applied to the aggregated system capital cost.

\section{Installation Phase}

The maturity of the proposed installation method for nonenduring elements has been assessed as TRL6 as the sole novel aspects of the proposed installation method is lowering the device to the sea-bed from a barge [22]. This has been demonstrated previously to be effective, albeit at a much smaller scale [20]. Based upon this assessment, the installation cost can be escalated to take account of the additional risk arising from the relative immaturity of specific installation methods.

\section{E. Disposal Phase}

The disposal process is assumed to follow that proposed elsewhere in the renewable energy sector [11], [32], in that the devices will be recovered from the seabed, and returned to land for decommissioning, whilst cabling will remain in situ on the sea bed, with cable terminals suitably buried. There are no significant structures onshore, so onshore decommissioning should pose negligible technical challenges. Surveys have shown that the Tidal stream device has no long-term effect on the sea-bed [20], so the sole remaining liability is likely to be related to residual cabling. In costing the decommissioning program, it is not clear if the costs of this continuing liability have been considered. However, in the context of the programme as a whole, these liabilities are assumed to be small enough to pose a negligible risk, with no cost escalation being necessary.

\section{F. Results}

Using data arising from the foregoing analysis, the overall cost of electricity can be calculated as summarised in $\S I I I . H$, and the LEC (Cost/MWh) is illustrated in Fig 6. As risks have been included as contingency, the standard deviation given is common to both the risk-adjusted and non-risk-adjusted cost distributions. Nominally, using a recent value for UK renewable energy credits (or ROCs) of £52.95 [33], and assuming the Scottish Government proposed banding for this technology of 3 ROCs per MWh produced [34], the effective commercial cost becomes around $£ 55.80 / \mathrm{MWh}$. However, if a return rate is of $5 \%$ required, the break-even price becomes $£ 154.22$ which is well above the wholesale price range within the current UK electricity market.

Cost/MWh Distribution

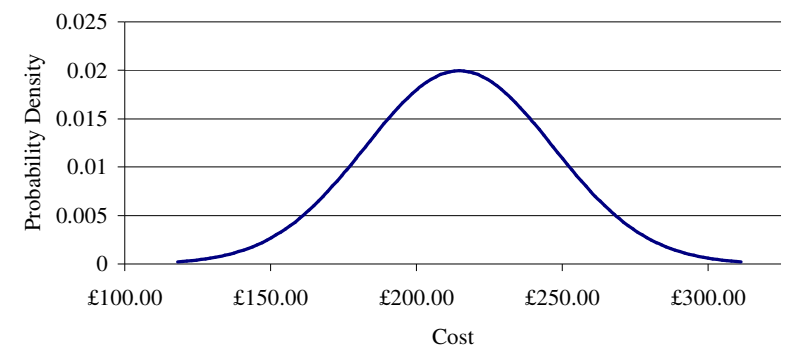

Fig 6. Cost of Electricity for Exemplar Assessment

\section{FURTHER RESEARCH}

The model proposed within this paper is intended as a framework to guide a due diligence assessment, applying the principles of Systems Engineering to ensure a full-system viewpoint is taken.

The current model demonstration relies upon heuristic cost escalation factors which in practice require verification using actual project data (potentially from similar sectors such as offshore wind) to lend validity to the results obtained. A key issue to highlight here is the uncertainty (and risk) relating to assessment of the level of skills possessed by providers (in particular device developers), and the degree to which these are appropriate to the task at hand. Whilst the approach presented here provides a useful and practical due diligence framework, further work is required to validate this approach

\begin{tabular}{lrrr}
\hline Parameter & Mean & Risk Adjusted Mean & Std Dev \\
\hline Capital Cost & $£ 13.66 \mathrm{M}$ & $£ 16.31 \mathrm{M}$ & $£ 1.37 \mathrm{M}$ \\
Installation Cost & $£ 1.38 \mathrm{M}$ & $£ 1.38 \mathrm{M}$ & $£ 0.13 \mathrm{M}$ \\
Disposal Cost & $£ 0.79 \mathrm{M}$ & $£ 0.79 \mathrm{M}$ & $£ 0.08 \mathrm{M}$ \\
Through-Life O\&M Cost & $£ 25.61 \mathrm{M}$ & $£ 9.84 \mathrm{M}$ & $£ 1.96 \mathrm{M}$ \\
Through Life Cost & $13.4 \%$ & $£ 28.32 \mathrm{M}$ & $£ 2.39 \mathrm{M}$ \\
Capacity Factor & $132.2 \mathrm{TWh}$ & - & $1.34 \%$ \\
Through Life Array Yield (10 devices over 25 years) & & - & $16.7 \mathrm{TWh}$ \\
Cost/MWh & & $£ 214.22$ & $£ 32.58$ \\
Breakeven Price (Assuming a target discount rate of 5\% per & & $£ 314.76$ & \\
annum) & & & \\
Internal Rate of Return (Assuming an effective electricity & & $4.4 \%$ \\
price of $£ 300 / \mathrm{MWh}$ including Renewable Energy & & & \\
Certificates (ROCs)) & & & \\
\hline
\end{tabular}


for specific applications.

\section{CONCLUSION}

The aim of a due diligence activity is to quantify the risk involved in a specific investment. In the case of a renewable energy scheme, this must include an assessment of the ability of the proposed system to deliver the required capability, based upon what is known about the technology to be used and the organisations delivering it.

A means of performing this assessment has been proposed, employing systems engineering methodologies to take a systematic view of a proposed scheme to be taken, encompassing the entire system, including its supporting systems through all stages of development. The inclusion of probabilistic parameters derived using Bayesian methods allows this whole system viewpoint to be reflected in a final LEC which provides both a justifiable estimate and a measure of uncertainty propagated from the input parameters. In this way, the model allows technical issues to be expressed in terms of their effect on the capability of the system, that is, to produce electricity at an economically feasible cost.

Although simple, the exemplar assessment demonstrates how the method may be used to combine the data available for a real system can be used to conduct an assessment, and show how the various risks involved can be incorporated into the final result.

In the current market, however, the financial feasibility may be secondary to other strategic interests and positioning. As the market develops towards commercial scale deployment, this model will become more relevant in attempting to predict which schemes have commercial potential and which are likely to fail to deliver their early promise.

\section{REFERENCES}

[1] I. Watson, P. Strachan and J. Armstrong, "Strategic Due Diligence: Facilitating Investment in Renewable Energy" presented at WREC X, Glasgow, UK, July 2008.

[2] M. A. Vallen and C.D. Bullinger, "The Due Diligence Process for Acquiring and Building Power Plants.” The Electricity Journal, vol. 12, no. 8, pp. 28-37, 1999.

[3] C.A. Morgan, H.M. Snodin and N.C. Scott, "Offshore Wind Economies of scale, engineering resource and load factors," Garrad Hassan and Partners, UK, Rep. 3914/BR/01, 2003

[4] L. Fingersh, M. Hand, and A. Laxson, "Wind Turbine Design Cost and Scaling Model,” NREL, Golden, Colorado, Tech Rep. NREL/TP-50040566, 2006

[5] C. Cameron and C. Cornelius, "A Systems-Driven Approach to Solar Energy R\&D" presented at IEEE Intl. Conf. on Systems of Systems Engineering, 2007.

[6] L.E. Eberly, T. A. Louis, "Bayes/frequentist compromise decision rules for Gaussian sampling" Journal of Statistical Planning and Inference, vol. 121, no. 2, pp. 191-207, 2004.

[7] W.M. Bolstad, "Bayesian Interference for Normal Mean" in Introduction to Bayesian Statistics, 2nd ed. Hoboken, New Jersey: Wiley, 2007, pp. 199-222.

[8] Ministry of Defence. (2010, Sep). What are Technology Readiness Levels (TRLs)? [Online] Available: http://www.aof.mod.uk/aofcontent/tactical/techman/content/trl_whataret hey.htm.
[9] D.J. Moorhouse, "Detailed Definitions and Guidance for Application of Technology Readiness Levels." Journal of Aircraft vol. 39, no. 1, pp, 190-192, 2002

[10] House of Commons. (2004) "Energy Act 2004" [Online] Available: http://www.legislation.gov.uk/ukpga/2004/20

[11] Greater Gabbard Offshore Winds Ltd, "Decommissioning Programme," Rep. 577000/403 - MGT100 - GGR - 107, 2007.

[12] D. Pearson D, "Decommissioning Wind Turbines In The UK Offshore Zone" presented at BWEA 23, Brighton, UK, 2001.

[13] Nuclear Energy Agency, International Energy Agency, Organisation for Economic Co-Operation and Development, "Projected Costs of Generating Electricity 2005 Update," 2005.

[14] Wolfram Research Inc. (2010, Oct) Central Limit Theorem. [Online] Available: http://mathworld.wolfram.com/CentralLimitTheorem.html

[15] Systems Engineering - System lifecycle processes, BS ISO/IEC 15288:2002, 2002

[16] B. Woodman, P. Baker, "Regulatory frameworks for decentralised energy", Energy Policy, vol. 39, pp. 4527-4531, 2008.

[17] Information Technology - Process Assessment, BS ISO/IEC 15504:2004, 2004.

[18] J. Hutt and M. Johnstone, "Skills for renewable energy in Scotland", Avayl Engineering, Inverness, UK, 2005.

[19] Scottish Hydro Electric Transmission Ltd, "Proposed HVDC Link from the Shetland Islands to Mainland Scotland - Consultation Document," 2008.

[20] Department for Trade and Industry, "Stingray Tidal Stream Energy Device - Phase 3,’Rep. URN 05/864, 2005.

[21] Shetland Islands Council, "Shetland in Statistics," 2003.

[22] I.G. Bryden, "The marine energy resource, constraints and opportunities." Marine Engineering, vol. 159, no. 2, pp. 55-65, 2006.

[23] HM Treasury, "Discounting" in The Green Book, TSO, London, UK, 2010, pp 26-28.

[24] J.D. Andrews, "Birnbaum and criticality measures of component contribution to the failure of phased missions." Reliability Engineering and. System Safety, vol. 93, no. 12, pp. 1861-1866, 2008.

[25] Department for Trade and Industry, "Stingray Tidal Stream Energy Device - Phase 2," Rep. URN 03/1433, 2003.

[26] Department for Business, Enterprise and Regulatory Reform, "Capital Grant Scheme for the North Hoyle Offshore Wind Farm - Annual Report: July 2006-June 2007,” Rep. URN 08/P47, 2007.

[27] Department for Trade and Industry, "Capital Grant Scheme for the North Hoyle Offshore Wind Farm - Annual Report: July 2005-June 2006," 2006.

[28] Department for Trade and Industry, "Capital Grant Scheme for the North Hoyle Offshore Wind Farm - Annual Report: July 2004-June 2005," 2005.

[29] Department for Trade and Industry, "Capital grant scheme for Scroby Sands offshore wind annual report: January 2006 - December 2006," Rep. 07/944, 2007.

[30] Department for Trade and Industry, "Capital grant scheme for Scroby Sands offshore wind annual report: January 2005 - December 2005," 2006.

[31] Department for Trade and Industry, "Capital grant scheme for offshore wind: Kentish Flats offshore wind farm annual report January 2006 December 2006," Rep. URN 07/1392, 2007.

[32] Department for Trade and Industry. (2006) Decommissioning of Offshore Renewable Energy Installations under the Energy Act 2004: Guidance Notes for Industry.

[33] Office of the Gas and Electricity Markets, "Renewables Obligation: Annual Report 2007-2008.”, Rep. 17/09, 2009.

[34] Scottish Government, "Modelling Changes to the Renewables Obligation,” Rep: ISBN 978075597285 2, 2008. 